\title{
The Correlation between Academic Success and Depressive Symptoms among Students
}

\author{
Amir Maliqi ${ }^{*}$, Ardita-Zeqaj-Maliqaj2\#, Islam-Isaac Borincaj-Cruss ${ }^{3 *}$ \\ ${ }^{1}$ Department of Psychology, University of Prishtina "Hasan Prishtina”, Prishtine, Kosovo \\ ${ }^{2}$ Faculty of Medicine, University of Prishtina "Hasan Prishtina", Prishtine, Kosovo \\ ${ }^{3}$ Faculty of Arts and Social Science, International University of Sarajevo, Sarajevo, Bosnia and Herzegovina \\ Email: bosia@ius.edu.ba
}

Received 27 August 2015; accepted 30 October 2015; published 3 November 2015

Copyright (C) 2015 by authors and Scientific Research Publishing Inc.

This work is licensed under the Creative Commons Attribution International License (CC BY). http://creativecommons.org/licenses/by/4.0/

cc (i) Open Access

\begin{abstract}
Depression is a state of low mood characterized by depressed mood, loss of interest or pleasure, decreased energy of the person, feelings of guilt, low self-esteem, and poor concentration. These problems could become chronic or repetitive and lead to substantial impairments in an individual's skills in relation to the daily care responsibilities, and depression can lead a person to make suicide. The present study aims: H1: Low academic success at the university has negative correlation with depression; H2: Girls tend to show more depressive symptoms compared with boys. This study included 102 students, conveniently selected by the Faculty of Medicine at the University of Prishtina "Hasan Prishtina" in Kosovo. As reported in the results section and after discussed, the findings (partially) support our hypotheses. More specifically, a correlation analysis showed that: Low success affects the appearance of depressive symptoms. Furthermore, an independentsample $t$-test showed that: there are no significant differences regarding to the gender in the appearance of depressive symptoms.
\end{abstract}

\section{Keywords}

Students, Academic Success, Depressive Symptoms, Kosovo

\section{Introduction}

Depression is a state of low mood characterized by depressed mood, loss of interest or pleasure, decreased energy of the person, feelings of guilt, low self-esteem, and poor concentration (APS, 2000). These problems

\footnotetext{
"The two authors are both Masters of Science (Ms.C.).

${ }^{\#}$ The author is a Doctor.
} 
could become chronic or repetitive and lead to substantial impairments in an individual's skills in relation to the daily care responsibilities, and depression could lead a person to make suicide (Weisz \& McCarty, 2001). Depression is a state of low mood and very widespread among adolescents and young adults. It could be the result of failures in school, family problems, peer problems, and also romantic failures (Svanum \& Zody, 2001).

Academic success in school has to do with how students realize the required objectives by teachers and this includes: dedication, commitment, performance, something which is estimated in the end and this estimate can be positive and negative. Moreover, this is considered as an academic achievement or academic productivity of the students (Hysenbegasi \& Haas, 2005).

Academic success or academic productivity is something that is estimated by teachers through various tests, performance and commitment, and if the students showed high academic productivity, they will be positively estimated and this would increase their self-esteem, while the opposite happen with those who will be negatively evaluated also they could receive feedback through teachers because of difficulties in learning, therefore they might start to have lower self-esteem, or inferior feelings (Andrews \& Wilding, 2004).

Learning difficulties could serve as an independent risk factor for depression, specifically, to young people (Herman, Lambert, Ialongo, \& Ostrander, 2007) and the main point of this study claims that poor success has negative correlation with depression. Furthermore, poor success at the university might be the result of many different factors: Low cognitive levels of students, lack of motivation, but when we have to do with young people then there enters: Family problems, interest in other things, peer problems, insignificant non-school activities, and afterward this result with the appearance of depressive symptoms and when these young people are aware about the position which have achieved and is not favorable at all, or success that might have, does not coincide with their expectations therefore, they will feel disappointed and become very depressed (Jaycox, Stein, Paddock, Miles, Chandra, Meredith, Leino, \& Kisch, 2005). Besides cognitive preparation, teachers should have developed the affective aspect as well and this will help them to understand much better problems and challenges which students may face in social terms and in learning (Borinca \& Maliqi, 2015).

Another issue related to lower academic success and depressive symptoms is that students could become aware about their cognitive deficits and also to feel powerless to change in this regard, hence their dissatisfaction may result with depressive symptoms and they could be deeply in these symptoms and might have inferiority feelings by comparing their success with other students that achieve higher academic success (Herman et al., 2007; Tanielian, Hickey, \& Bumam, 2009).

A different issue raised in this study is that females tend to display more depressive symptoms than males, all this because females might be more sensitive, and may experience harder the failures compared with males which are indicated insensitive about that (Hankin \& Abramson, 1999). The other reason could be the fear of social circles and the model that they must show to the family and community, when the poor success does not represent a positive image for the family or community compared with males who do not care for the family or community expectations (Piccinelli \& Wilkinson, 2000).

\section{The Present Study}

Focus of the study: The Correlation between Academic Success and Depressive Symptoms among Students in Kosovo. The purpose of this study: is to disintegrate the connectivity between poor success at university and the display of depressive symptoms, and gender differences as well. Specifically:

1) Is there any connection between depression and low academic success?

2) Which gender tends to display more depressive symptoms because of academic success?

There are two hypotheses in this research, one of them is primary and the other one is known as secondary. The primary hypothesis of is: Low academic success at the university has negative correlation with depression. While the other hypothesis is: Females tend to show more depressive symptoms compared with males.

\section{Methodology of Study}

The method used was quantitative method and data were analyzed through SPSS.

\subsection{Participants and Procedure}

The total number of participants in this study was 102 students. This number was selected conveniently by students of the Faculty of Medicine at the University of Prishtina" Hasan Prishtina" Kosovo. Participants are from 
both genders, where 58 of them are females and 44 of them are males, ages 18, 19, 20 and 21 years old.

\subsection{Instrument}

Beck Depression Inventory. An adaptation of Beck Depression Inventory by Beck and colleagues (1961) which contains 21 questions with different responses, plus one additional question related to their grade point average (GPA) or success in the last semester, that will give us information about the success and depression among students. One example of Beck Depression Inventory: Participants were asked to express their feelings with four items (e.g., "Sadness"; I do not feel sad, I feel sad much of the time, I am sad all the time, I am so sad or unhappy that I can't stand it.) Beck Depression Inventory in this study showed a reliable internal consistency $(\alpha=.88)$.

\section{Results of Study}

In this research, there were 102 participants, of which 44 of them were males and 58 females. Their ages ranged from 18 - 21 years old. Specifically, those of age 18 were 14 subjects; from them 10 were females and 4 males. There were 31 subjects who were about 19 years old, consisting of 13 female's and 18 males. Those of age, 20 were 38 subjects; from them 23 subjects were females and 15 males. Also, there were 21 subjects who were about 18 years old, including 12 females and 7 males. Of these subjects from urban areas were 53students, while the rural areas were 49 of them.

In connection with this, is conducted correlation between depression scores and success where we have this statistical production $(\mathrm{r}=-.61$ and $p=.00)$. Therefore, this correlation is negative, significant and shows the linkup between the two variables mentioned above (Table 1, Table 2), where the reduction of academic success caused an increase of the depressive symptoms.

Table 1. Correlation between academic success and depressive symptoms.

\begin{tabular}{|c|c|c|c|}
\hline \multicolumn{2}{|c|}{ Correlation } & \multirow{2}{*}{$\begin{array}{c}\text { Variable } \\
1\end{array}$} & \multirow{2}{*}{$\begin{array}{c}\text { Success } \\
-.61\end{array}$} \\
\hline Depression & Pearson Correlation & & \\
\hline & Sig. (2-tailed) & & 0 \\
\hline & $\mathrm{N}$ & 102 & 102 \\
\hline \multirow[t]{3}{*}{ Success } & Pearson Correlation & -.61 & 1 \\
\hline & Sig. (2-tailed) & 0 & \\
\hline & $\mathrm{N}$ & 102 & 102 \\
\hline
\end{tabular}

Table 2. Gender differences in depression and academic success.

\begin{tabular}{cccccc}
\hline \multicolumn{7}{c}{ Group Statistics } \\
Variable & Gender & $\mathrm{N}$ & Mean & Std. Deviation & S.E. Mean \\
\hline Male & 44 & 9.41 & 7.28 & 1.1 \\
& Female & 58 & 10.19 & 9.76 & 1.28 \\
\hline
\end{tabular}

\begin{tabular}{|c|c|c|c|c|c|c|c|c|c|}
\hline & $\mathrm{F}$ & Sig. & $\mathrm{T}$ & df & Sig. (2-tailed) & Mean Difference & Std. Error Difference & Lower & Upper \\
\hline $\begin{array}{c}\text { Attitudes/Equal } \\
\text { Variances Assumed }\end{array}$ & .94 & .33 & -.44 & 100.00 & .66 & -.78 & 1.69 & -4.13 & 2.57 \\
\hline $\begin{array}{l}\text { Equal Variances } \\
\text { Not Assumed }\end{array}$ & & & -.46 & 99.98 & .64 & -.78 & 1.69 & -4.13 & 2.57 \\
\hline
\end{tabular}


Related to the depressive symptoms: Males reported $X=9: 41$ and 7:28 DS, while Females $X=10.19$ and DS 9.76 and T-test $(100)-.44$ and $p=.64$ therefore, there are no significant differences regarding to the gender in the display of depressive symptoms.

\section{Discussion}

The main findings in this study are: Low success affects the appearance of depressive symptoms, in this case, the hypothesis: Low academic success at the university has negative correlation with depression finds support specifically, how lower success is, the greater will be the depression. While, the other hypothesis: Females tend to show more depressive symptoms compared with males; does not find support because the success manifested in a similar manner for both genders and in the same way both genders could show depressive symptoms as a result of this. Results from this study are similar to many international researches regarding to the low academic success and depressive symptoms. The study conducted in 2005 at the University of Michigan in the US regarding to this matter claims: One of the main reasons that could affect students with depressive symptoms are the achieved results that does not coincide with their expectations and dissatisfaction for their cognitive domain (Hysenbegasi, 2005). Even the conducted research in 2009 at the University of Michigan about the impact of depressive symptoms on academic performance related to gender differences stress out: there are no gender differences in that aspect because nowadays education is more than necessary for all people and all people are equal therefore, failures are experienced in a similar manner from both genders (Jaycox, 2005).

\section{Conclusion}

This study tries to understand the correlation between academic success and display of depressive symptoms. The results of the present study confirm a strong correlation between low academic success and display of depressive symptoms. However, there are no significant differences between males and females in show of the depressive symptoms, and making it clear that education is important for both genders and in case of failure, then this could experience similarly. In conclusion, one limitation of this study relates to the selection of the sample only at the Faculty of Medicine and not other faculties at the University of Pristina, where with a probability sample and with a large number of participants we could make generalizations throughout Kosovo.

\section{References}

American Psychiatric Association (APS) (2000). Diagnostic and Statistical Manual of Mental Disorders (4th ed., text rev.). Washington, DC: American Psychiatric Association.

Andrews, B., \& Wilding, J. M. (2004). The Relation of Depression and Anxiety to Life-Stress and Achievement in Students. British Journal of Psychology, 95, 509-521. http://dx.doi.org/10.1348/0007126042369802

Beck, A. T., Ward, C. H., Mendelson, M., Mock, J., \& Erbaugh, J. (1961) An Inventory for Measuring Depression. Archives of General Psychiatry, 4, 561-571. http://dx.doi.org/10.1001/archpsyc.1961.01710120031004

Borinca, I., \& Maliqi, A. (2015). The Influence of Teachers on Increasing Student's Motivation to the Ismail Qemaili High School in the City of Kamenica, Kosovo. Psychology, 6, 915-921. http://dx.doi.org/10.4236/psych.2015.68089

Hankin, B. L., \& Abramson, L. Y. (1999). Development of Gender Differences in Depression: Description and Possible Explanations. Annals of Medicine, 31, 372-379. http://dx.doi.org/10.3109/07853899908998794

Herman, K. C., \& Ostrander, R. O. (2007). The Effects of Attention Problems on Depression: Developmental, Cognitive, and Academic Pathways. School Psychology Quarterly, 22, 483-510. http://dx.doi.org/10.1037/1045-3830.22.4.483

Hysenbegasi, A., Hass, S. L., \& Rowland, C. R. (2005). The Impact of Depresion on the Academic Productivity of University Students. The Journal of Mental Health Policy and Economics, 8, 145-151.

Jaycox, L. H., Stein, B. D., Paddock, S., Miles, J. N. V., Chandra, A., Meredith, L. S., Leino, E. V., \& Kisch, J. (2005). Correlates and Predictors of Depression in College Students: Results from the Spring 2000 National College Health Assessment. American Journal of Health Education, 36, 66-74. http://dx.doi.org/10.1080/19325037.2005.10608162

Piccinelli, M., \& Wilkinson, G. (2000). Gender Differences in Depression. Critical Review. The British Journal of Psychiatry, 177, 486-492. http://dx.doi.org/10.1192/bjp.177.6.486

Svanum, S., \& Zody, Z. B. (2001). Psychopathology and College Grades. Journal of Counseling Psychology, 48, 72-76. http://dx.doi.org/10.1037/0022-0167.48.1.72

Tanielian, T., Hickey, S., \& Burnam, M. A. (2009). Impact of Teen Depression on Academic, Social and Physical Functioning. 
PEDIATRICS, 124, e596-e605. http://dx.doi.org/10.1542/peds.2008-3348

Weisz, J. R., Southam-Gerow, M. A., \& McCarty, C. A. (2001). Control Related Beliefs and Depressive Symptoms in Clinic-Referred Children and Adolescents: Developmental Differences and Model Specificity. Journal of Abnormal Psychology, 110, 97-109. http://dx.doi.org/10.1037/0021-843X.110.1.97 